\title{
48. IN-HOLE TEMPERATURES AND HEAT FLOW, SITE 319, LEG 34
}

\author{
J.M. Ade-Hall, Department of Geology, Dalhousie University, Halifax, Nova Scotia, Canada \\ Richard Von Herzen, Woods Hole Oceanographic Institution, Woods Hole, Massachusetts \\ and \\ Al Erickson, Department of Geology, University of Georgia, Athens, Georgia
}

\section{INTRODUCTION}

The measurement of heat flow in the ocean basins provides important constraints on models of the formation of crustal plates (Sclater and Francheteau, 1970) and on the details of hydrothermal activity and endothermic reactions within the upper parts of the plates (Hyndman and Rankin, 1972; Anderson, 1972). The principal advantage of heat-flow measurements in deep drill holes is that uncertainties about the downward continuation of gradients observed within the top few meters of sediment can be avoided by making measurement over a greater range of depths. A sophisticated down-hole temperature measuring instrument (DHI) has been developed for use with the Glomar Challenger drilling equipment, and successful measurements have been made during a number of DSDP legs (Erickson et al., 1975). In this report we describe two down-hole temperature measurements made at Site 319 of Leg 34.

\section{EXPERIMENTAL METHOD}

Both temperature measurements were made using a 19-in. $(48.3 \mathrm{~cm})$ extender and a $23 / 4$-in. $(7.9 \mathrm{~cm})$ probe attached to the DHI. The DHI lowered through the drill string rapidly attached to a standard core barrel until the core barrel "latched in" to the drill. Upon lowering the drill string to the bottom of the hole, it was noted that the sediment was unable to support the weight of the drill string during measurement intervals, and the bit was lowered by an unrecorded but small distance at least once during the measurement at 47.5 meters subbottom, and 12 times during the measurement at 76.0 meters. Complete temperature recordings, with good mud line values, were obtained on both runs.

\section{RESULTS}

\section{Bottom-Hole Temperature and Heat Flow at 47.5 Meters}

Figure 1 shows the temperature versus time record for the 47.5 meters subbottom run. Some degree of instrumental malfunction is indicated during the measurements at 47.5 and 76.0 meters subbottom. At both levels sequential groups of five temperatures in the data printout show excessive within-block variation, with a standard deviation of a single temperature within any group equal to about $0.1^{\circ} \mathrm{C}$. For this reason the plots shown in Figures 1 and 2 are based on blockaverage temperatures and, as such, show what appear to be a physically sensible record of temperature with time. The double thermal impulse pattern during the first 4 min probably corresponds to the latch-in process, followed 2 min later by penetration of the sediment. A note in the driller's log states that drill-string weight was gained immediately following bottom penetration and after waiting approximately $6 \mathrm{~min}$, the bit was again lowered, giving rise to a second clearly marked thermal pulse at about 39.5 min elapsed time. A small thermal pulse may also have occurred at about 38 min elapsed time, but the interpretation here of the record is subjective. Pullout is clearly shown at $44 \mathrm{~min}$, that is, $10 \mathrm{~min}$ after initial penetration.

The problem in interpreting this record is in the incomplete decay of any one thermal pulse before the onset of succeeding thermal events, caused in this case by drill-string lowering and pullout. Under ideal conditions undisturbed bottom-hole temperatures would be obtained during the latter part of the 10-min interval while the DHI is in contact with the sediment. In this case, pulses were only allowed to decay for 5 and $4.5 \mathrm{~min}$ respectively, before the onset of new thermal events. Following Erickson et al. (1975) and Bullard (1954), we attempted to obtain equilibrium (in situ) sediment temperatures by assuming that, for long times, temperature is inversely proportional to time. A plot of temperature versus $(1 /$ time $)$ should thus be linear and have its intercept at $1 / t=0$ at a temperature equal to the equilibrium temperature. With two distinct thermal pulses and no decay times in excess of $5 \mathrm{~min}$, temperature data obtained at 47.5 meters subbottom meets the analytical requirements poorly. This is evident from Figure 2 where the two pulses are shown plotted separately against the inverse of time elapsed since pulse onset. While reasonably linear distributions of values occur, the intercepts give different equilibrium temperature values of $4.0^{\circ} \mathrm{C}$ and $3.4^{\circ} \mathrm{C}$, respectively. Better agreement between the equilibrium temperatures for the two pulses might be obtained by fitting the two pulses to expression (2) of Bullard, (1954). In order to do this, a number of physical properties of the DHI, such as the water equivalent per unit length, would have to be determined. For an approximate determination of heat flow, it seems likely that the $3.4^{\circ} \mathrm{C}$ value is closer to the true equilibrium temperature since the data used to obtain the $4.0^{\circ} \mathrm{C}$ value likely to consist of two unresolved pulses. For this reason a weighted mean equilibrium temperature for the 47.5 -meter run of $3.6 \pm 0.4^{\circ} \mathrm{C}$ is proposed. The harmonic mean of the 16 preliminary sediment thermal conductivity values, giving unit weight to the mean value for each 10 -meter interval, over the depth range $0-50$ meters subbottom, is $2.22 \pm 0.45$ $\mathrm{mcal} / \mathrm{cm} \mathrm{sec}{ }^{\circ} \mathrm{C}$ (error of the mean). A heat flow at this depth of $0.80 \pm 0.21 \mu \mathrm{cal} / \mathrm{cm}^{2} \mathrm{sec}$ is indicated. The error 


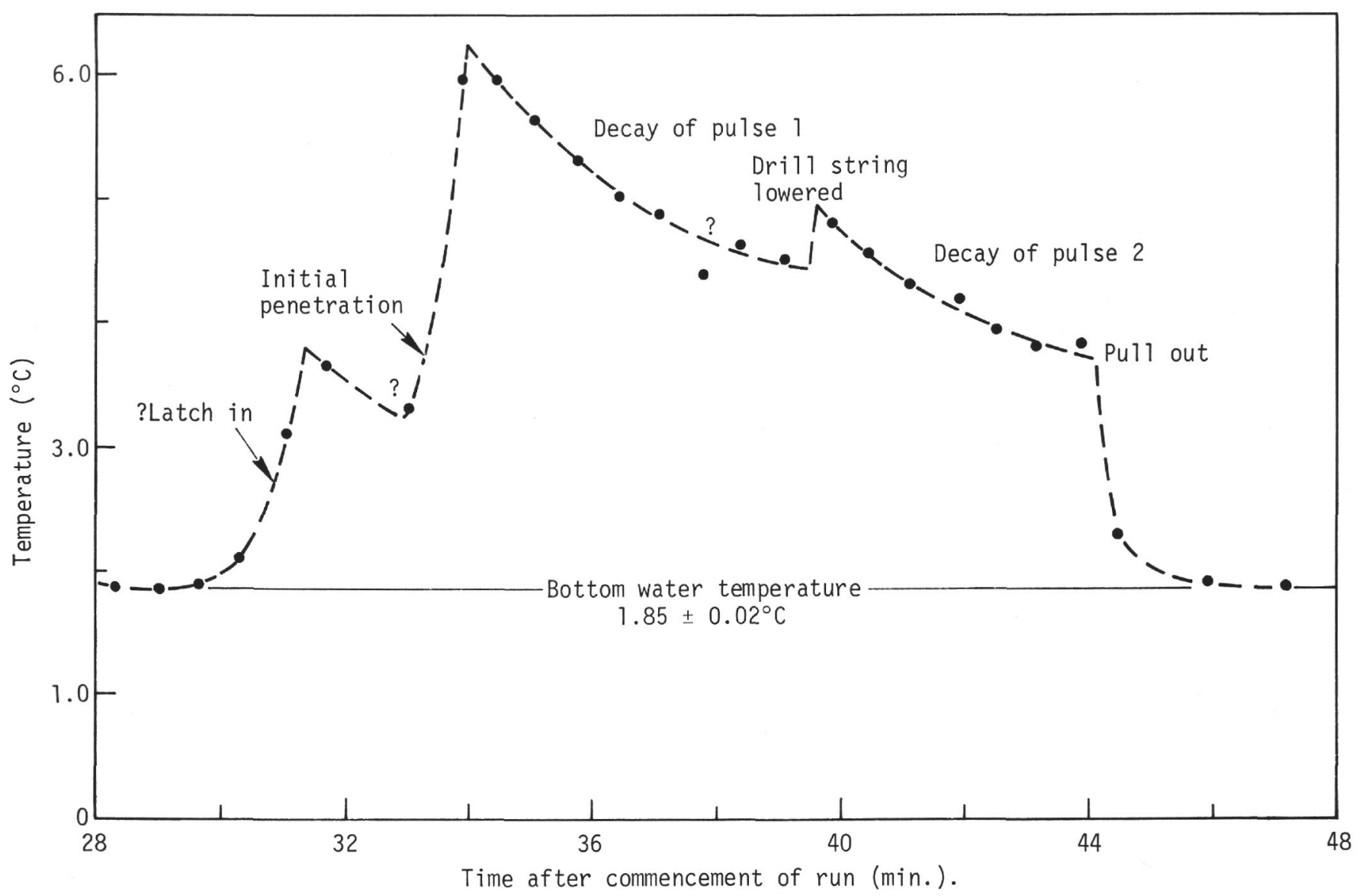

Figure 1. Variation of temperature with time, 47.5 meters subbottom run, Site 319. Note: Each point represents the average of a block of five temperature determinations.

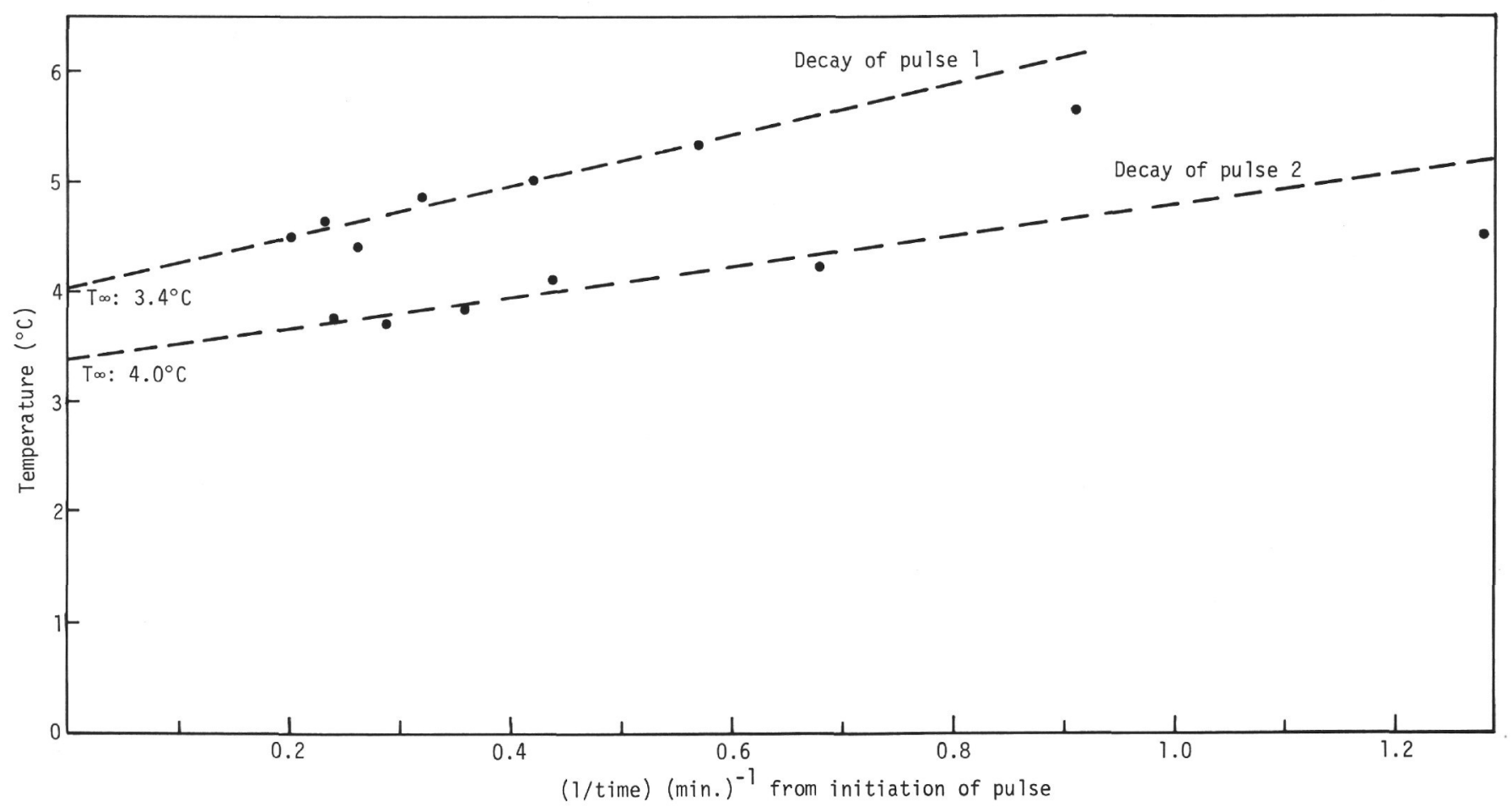

Figure 2. Temperature versus the inverse of time for the decay of two thermal pulses, 47.5-meter run, Site 319. 
represents both the uncertainty in the poorly defined equilibrium temperature and in the preliminary conductivity values.

\section{Bottom-Hole Temperature and Heat Flow at $\mathbf{7 6 . 0}$ meters}

At this depth an attempt was made to keep the DHI in contact with undisturbed sediment by lowering the drill string each time the weight indicator showed that sediment flow had occurred. Lowering took place 12 times during the 20-min interval when the DHI was on the bottom. Each lowering operation produced a thermal pulse and from Figure 3 it is evident that the decay of individual interval pulses cannot in general be resolved. The decay of the final thermal pulse before pull out is sufficiently well developed to show that the equilibrium temperature is less than $6.0^{\circ} \mathrm{C}$. The harmonic mean of the 33 preliminary thermal conductivity values is 2.36 $\pm 0.26 \mathrm{mcal} / \mathrm{cm} \mathrm{sec}{ }^{\circ} \mathrm{C}$ (error to the mean) to 80 meters and the corresponding heat flow must be less than 1.3 $\mu \mathrm{cal} / \mathrm{cm}^{2} \mathrm{sec}$.

\section{CONCLUSIONS AND RECOMMENDATIONS}

Clearly the best estimate of the heat flow at Site 319 cannot be given more exactly than close to or a little less than $1 \mu \mathrm{cal} / \mathrm{cm}^{2}$ sec (Figure 4). The value is probably significantly less than the average of $1.54 \mathrm{HFU}$ for the $5^{\circ} \times 5^{\circ}$ area including the site given by Langseth and von Herzen (1971). However, inclusion of some high heat flow values from the crest of the East Pacific Rise is likely to make this mean value an unreliable guide for the Bauer Deep. It is likely that the Site 319 value is close to the "normal" values obtained for the Bauer Deep by participants in the Nazca Plate Project.

The main recommendation arising from Leg 34 experience is that attention should be given to modification of the DHI to insure thermal contact between the probe and undisturbed sediment. At present it seems that if the sediment is soft enough for good contact to be made, it is also likely to flow under the weight of the drill string during the measurement cycle. A possible solution might be in a spring-loaded sensing element which would be fired into the undisturbed sediment sufficiently far ahead of the drill bit. This should ensure continuous contact with undisturbed sediment regardless of whether flow took place in the immediate vicinity of the drill bit.

\section{ACKNOWLEDGMENTS}

Credit must be given to Allen Porter who operated the DHI successfully at Site 319 and reduced the taped temperature data to a form suitable for analysis. Dr. R.D. Hyndman was kind enough to give a critical reading to the first draft of this chapter.

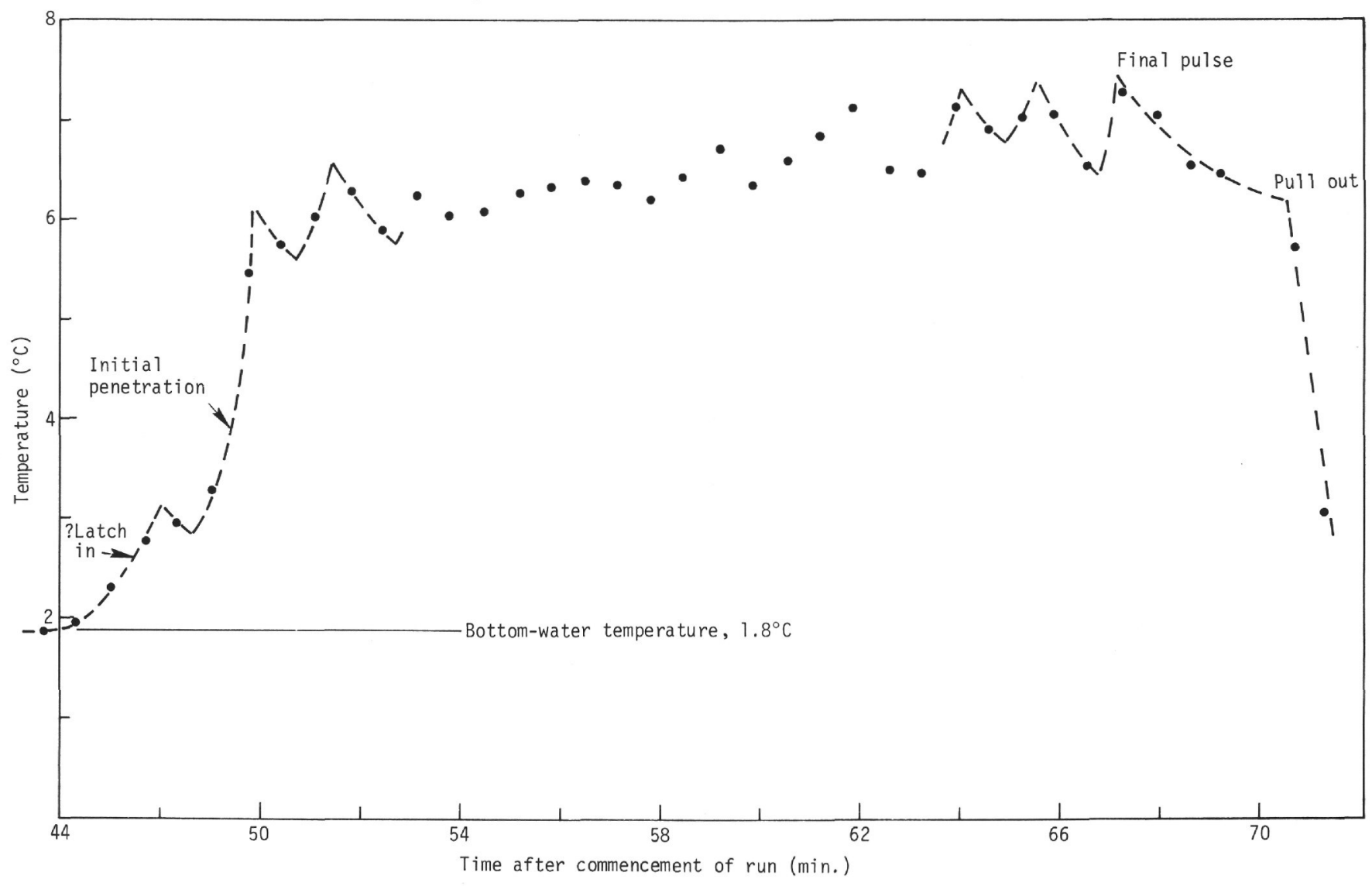

Figure 3. Variation of temperature with time, 76.0-meter subbottom run, Site 319. Note: Each point represents the average of a block of five temperature determinations. 

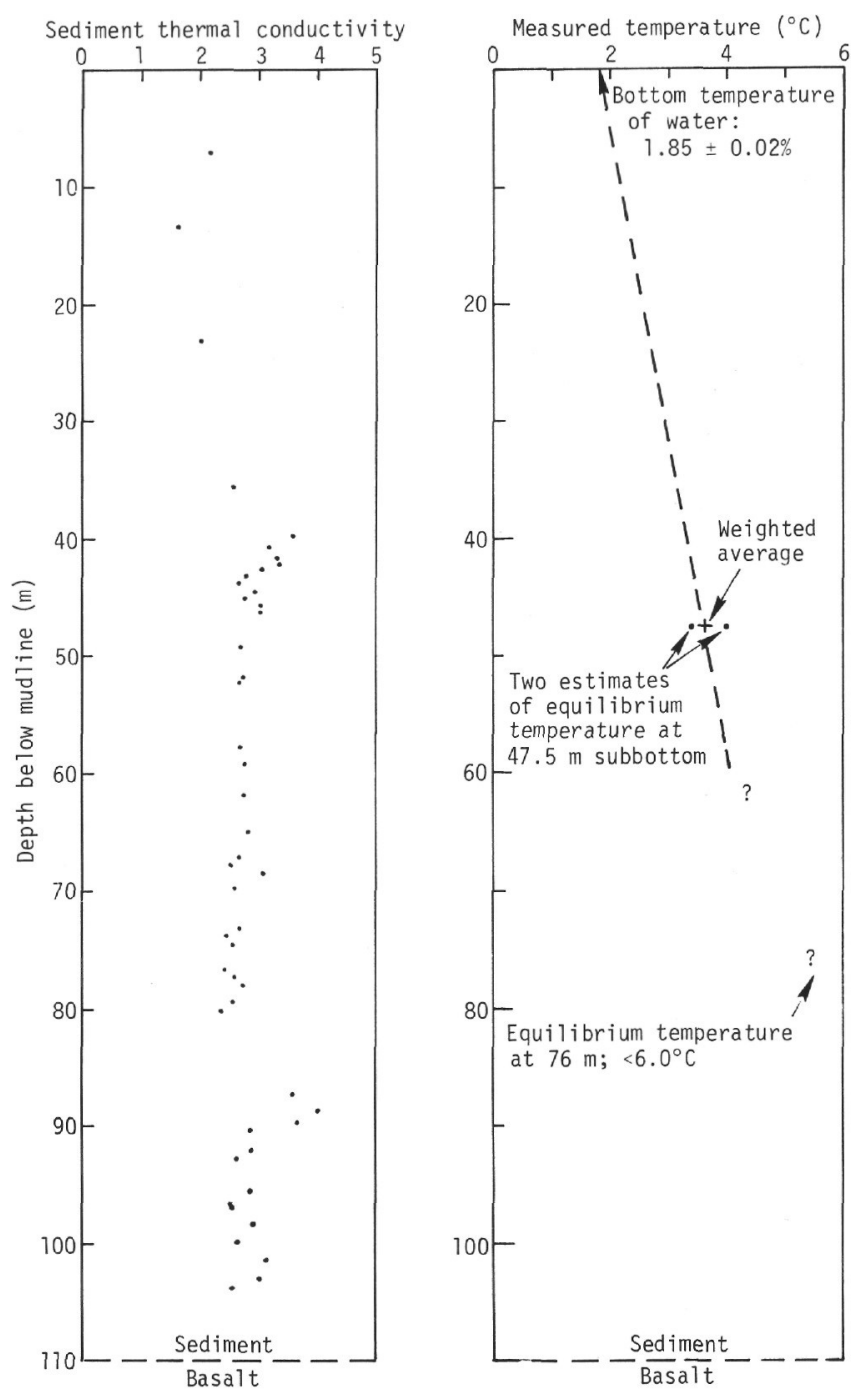

Figure 4. Variation of thermal conductivity of sediments and bottom-hole temperature with depth at Hole 319.

\section{REFERENCES}

Anderson, R.N., 1972. Petrologic significance of low heat flow on the flanks of slow spreading midocean ridges: Geol. Soc. Am. Bull., v. 83, p. 2947-2956.

Bullard, E.C., 1954. The flow of heat through the floor of the Atlantic Ocean: Proc. Roy. Soc. London, Sci. A, v. 222, p. 408.

Erickson, A.J., von Herzen, R.P., Sclater, J.G., Girdler, R., Marshall, B.V., and Hyndman, R.D., 1975. Geothermal measurements in deep sea drill holes. J. Geophys. Res., v. 80 , p. $2515-2528$.
Hyndman, R.D. and Rankin, D.S., 1972. The Mid-Atlantic Ridge near $45^{\circ} \mathrm{N}$. Heat flow measurements: Canadian J. Earth Sci., v. 12, p. 664-670.

Langseth, M.S. and von Herzen, R.P., 1971. Heat flow through the floor of the world oceans, page 299. In Maxwell, A.E. (Ed.) The sea, v. 4, pt. 1: New York (Wiley Interscience).

Sclater, J.G. and Francheteau, J., 1970. The implications of terrestrial heat-flow observations on current tectonic and geochemical models of the crust and upper mantle of the earth: Geophys. J., v. 20, p. 509-542. 